Revista Universo Contábil, ISSN 1809-3337
Blumenau, v. 16, n. 4, p. 50-69, out./dez., 2020

\title{
METODOLOGIAS ATIVAS E A APRENDIZAGEM SIGNIFICATIVA: UM ESTUDO COM ALUNOS DA DISCIPLINA DE ANÁLISE DE CUSTOS
}

\section{ACTIVE METHODOLOGIES AND MEANINGFUL LEARNING: A STUDY WITH STUDENTS FROM THE DISCIPLINE OF COST ANALYSIS}

\section{METODOLOGÍAS ACTIVAS Y EL APRENDIZAJE SIGNIFICATIVO: UN ESTUDIO CON ALUMNOS DE LA ASIGNATURA ANÁLISIS DE COSTOS}

Recebido em: 03-03-2020

Avaliado em: 07-07-2021

Reformulado em: 02-08-2021

Aceito para publicação em: 29-08-2021

Publicado em: 26-11-2021

Editor Responsável: Marcia Zanievicz da Silva
Isolfi Vieira Rocha Neto ${ }^{1}$

Edvalda Araújo Leal ${ }^{2}$

\section{RESUMO}

O estudo analisou se o uso de metodologias ativas na disciplina de Análise de Custos do curso de Ciências Contábeis contribui para uma aprendizagem significativa dos alunos de uma Instituição de Ensino Superior pública. À luz da Teoria da Assimilação de David Ausubel, desenvolveu-se uma pesquisa com abordagem mista no $2^{\circ}$ semestre letivo de 2018. A população deste estudo é composta por 87 alunos, distribuídos em dois turnos: integral e noturno. Na etapa quantitativa, foi utilizado o quase-experimento com um grupo de controle não equivalente. Para isso, foram formados dois grupos amostrais (Experimental e de Controle) e o tratamento foi conduzido em duas etapas. Foram aplicados questionários com o objetivo de identificar o perfil socioeconômico dos alunos, bem como Testes de Conhecimentos para avaliar o desempenho acadêmico. Os dados obtidos por meio dos questionários foram tratados por meio de análise descritiva e testes de comparações de médias. Na sequência, realizou-se a Etapa Qualitativa, com o propósito de examinar a perspectiva dos alunos acerca do uso das metodologias ativas. A percepção dos alunos foi coletada por intermédio de entrevistas de grupos focais. Para interpretar as declarações dos entrevistados, procedeu-se a técnica da análise de conteúdo. Ambas as etapas experimentais deste estudo demonstraram que houve aumento significativo do desempenho acadêmico dos alunos submetidos às metodologias ativas. Alinhado a este achado, os relatos dos alunos revelaram que as condições necessárias para a ocorrência da aprendizagem significativa (conhecimento prévio disponível; conteúdo potencialmente significativo; disposição em aprender) foram criadas quando usadas as metodologias ativas.

Palavras-chave: Metodologias ativas de ensino. Teoria da Assimilação. Análise de Custos. Storytelling. Método do caso. Trabalho de campo.

\footnotetext{
${ }^{1}$ Mestre em Ciências Contábeis pela Universidade Federal de Uberlândia; E-mail: isolfineto@gmail.com

${ }^{2}$ Doutora em Administração pela Fundação Getúlio Vargas (SP); Professora adjunta da Universidade Federal de Uberlândia; E-mail: edvalda@ufu.br
}

Agradecemos ao Conselho Nacional de Desenvolvimento Científico e Tecnológico (CNPq) e à Fundação de Amparo à Pesquisa do Estado de Minas Gerais (FAPEMIG) pelo suporte ao projeto de pesquisa. 


\begin{abstract}
The study analyzed whether the use of active methodologies in Cost Analysis in the Accounting course contributes to meaningful learning for students at a public higher education institution. Based on David Ausubel's Theory of Assimilation, we developed mixed approach research in the 2nd semester of 2018. The population of this study is composed of 87 students, distributed into two groups: full-time and part-time courses. In the quantitative stage, it used a quasi-experiment with a non-equivalent control group. We formed two sample groups (Experimental and Control) and conducted the treatment in two stages. We applied questionnaires to identify students' socioeconomic profiles and Knowledge Tests to assess academic performance. We treated the data obtained in the questionnaires through descriptive analysis and tests of comparisons of means. Then, we carried out the Qualitative Stage to examine the students' perspective on active methodologies. We collected the students' perceptions through interviews in focus groups. We used the content analysis technique to interpret the interviewees' statements. Both experimental stages of this study demonstrated a significant increase in the academic performance of students submitted to active methodologies. Similarly, the students' statements revealed that using active methodologies creates the necessary conditions for the occurrence of significant learning (prior knowledge available; potentially significant content; willingness to learn).
\end{abstract}

Keywords: Active teaching methodologies. Assimilation Theory. Cost analysis. Storytelling. Case method. Fieldwork.

\title{
RESUMEN
}

El estudio analizó si el uso de metodologías activas en la asignatura de Análisis de Costos del curso de Ciencias Contables contribuye a un aprendizaje significativo de los alumnos de una Institución de Enseñanza Superior pública. El estudio fue realizado bajo la Teoría de la Asimilación de David Ausubel. Para tanto, se desarrolló una investigación con abordaje mixta en el 2do semestre de 2018. La populación de este estudio está compuesta por 87 alumnos, divididos en dos turnos: integral y nocturno. En la etapa cuantitativa, fue utilizado el casi-experimento con un grupo de control no equivalente. Para eso, se formaron dos grupos de muestra (Experimental y de Control) y el tratamiento fue conducido en dos etapas. Fueron aplicados cuestionarios con el objetivo de identificar el perfil socioeconómico de los alumnos, así como Pruebas de Conocimiento para evaluar el rendimiento académico. Los datos obtenidos a través de los cuestionarios fueron tratados por un análisis descriptivo y tests de comparaciones de medias. A continuación, se realizó la Etapa Cualitativa, con el propósito de examinar la perspectiva de los alumnos acerca del uso de las metodologías activas. La percepción de los alumnos fue recogida por intermedio de entrevistas con grupos específicos. Para interpretar las declaraciones de los entrevistados, se procede la técnica del análisis de contenido. Ambas etapas experimentales de este estudio demuestran que hubo subida significativa del rendimiento académico de los alumnos sometidos a las metodologías activas. Junto a ese descubrimiento, los relatos de los alumnos revelaron que las condiciones necesarias para la ocurrencia del aprendizaje significativo (conocimiento previo disponible; contenido potencialmente significativo; disposición para aprender) fueron creados.

Palabras-clave: Metodologías activas de enseñanza. Teoría de la Asimilación. Análisis de Costos. Storytelling. Método de caso. Trabajo de campo.

\section{INTRODUÇÃO}

O amplo campo de atuação dos profissionais contábeis demanda que eles estejam capacitados a realizar atividades técnicas da profissão, e que estejam aptos a "compreender o contexto no qual se 
inserem, de interpretar os fenômenos socioculturais e assim promover ações alternativas e viáveis às demandas de um mundo cada vez mais excludente" (Laffin, 2015, p. 59). Tratando-se do profissional que atua na área de Contabilidade de custos, isso não é diferente, visto que, apesar de importante, ela deixou de focar exclusivamente na mensuração de estoques e passou a ter também um papel gerencial relevante no processo decisório das organizações, de mensuração e estudo das informações disponíveis aos usuários internos (Martins, 2010).

Cientes das exigências do mercado de trabalho, os alunos dos cursos de Contabilidade buscam uma formação profissional que os prepare para ingressar, manter-se e progredir no campo profissional. Como consequência disso, os professores e os gestores acadêmicos das Instituições de Ensino Superior (IES) da área contábil são desafiados a refletirem se o processo de ensino dos cursos de Contabilidade está promovendo, de fato, uma formação adequada e suficiente para esses alunos (Silva, Santos, Cordeiro Filho, \& Bruni, 2014).

No processo de ensino-aprendizagem, o professor, ao selecionar e planejar as metodologias de ensino, avalia uma série de fatores relacionados ao aluno, ao conteúdo a ser ensinado, à estrutura física disponível e ao contexto institucional. As metodologias de ensino são os caminhos (não os fins) que o professor se propõe a seguir com a finalidade de alcançar os objetivos educacionais. Na visão de Anastasiou e Alves (2015), o principal objetivo educacional é a apropriação, por parte dos alunos, de um conhecimento fundamental à sua formação.

No processo de ensino-aprendizagem dos cursos brasileiros de Contabilidade, a abordagem de ensino tradicional é preponderante (Gilioli et al., 2016). Predomina, nessa abordagem, a transmissão de uma grande quantidade e variedade de conteúdos pelos professores por meio de aulas expositivas, enquanto os alunos cumprem o papel de receptores de informações e conhecedores (ou memorizadores) universais de toda a amplitude do conteúdo (Mizukami, 1986).

Na contramão dessa tendência, Gilioli et al. (2016) destacam outras metodologias de ensino com propostas de aprendizagem ativas que estão sendo crescentemente incorporadas nas salas de aulas dos cursos de Contabilidade, como o método do caso, atividades práticas e debates. Esses são alguns exemplos de atividades por meio das quais os alunos passam a exercer um papel ativo no processo de ensino-aprendizagem e deixam de exercer somente a posição de receptores passivos de informações (Brickner \& Etter, 2008), as quais são denominadas metodologias ativas de ensino.

Tomando como fonte a literatura educacional contábil, estudos descrevem o uso de diversos modelos de metodologias ativas, bem como evidenciam que elas proporcionam benefícios para o processo de ensino-aprendizagem, desde melhorias no desempenho acadêmico até o desenvolvimento de competências profissionais (Bremser \& White, 2000; Kern, 2002; Lightbody, 2002; Brickner \& Etter, 2008; Krom \& Williams, 2011; Vendramin, 2018).

Os métodos ativos de ensino são pautados na problematização de situações familiares do cotidiano dos alunos ou que fazem parte da rotina do ambiente profissional em que eles, possivelmente, irão atuar. Isso motiva os alunos a refletirem sobre o novo material de estudo e a ressignificá-lo a partir de suas experiências anteriores (Mitre et al., 2008), solidificando a conexão entre teoria e prática, de modo que o conteúdo seja aprendido significativamente (Paiva, Parente, Brandão, \& Queiroz, 2016), passando a ser um conhecimento estável e durável do aluno.

Dentre as teorias cognitivas de aprendizagem que oferecem suporte teórico à validade das metodologias ativas para que a aprendizagem seja significativa, aborda-se a Teoria da Assimilação de David Ausubel. Tanto a teoria ausubeliana quanto as metodologias ativas valorizam os saberes prévios dos alunos, bem como destacam a relevância do conteúdo a ser aprendido e demandam que eles tenham uma predisposição para a assimilação, construção e transformação do conhecimento (Diesel, Baldez, \& Martins, 2017; Vendramin, 2018).

Diante do exposto, na tentativa de verificar os benefícios da diversificação das metodologias de ensino para o processo de ensino-aprendizagem dos cursos de Ciências Contábeis, formula-se o seguinte problema de pesquisa: o uso de metodologias ativas na disciplina de Análise de Custos do curso de Ciências Contábeis contribui para uma aprendizagem significativa? 
Em linha com o problema de pesquisa, o presente estudo foi elaborado com o propósito geral de analisar a contribuição de metodologias ativas para uma aprendizagem significativa na disciplina de Análise de Custos do curso de Ciências Contábeis. O objetivo proposto é examinado à luz da Teoria da Assimilação de David Ausubel.

O presente estudo contribui com a literatura que investiga a aplicação de metodologias ativas em disciplinas da área de custos, bem como com os trabalhos sobre o processo de ensinoaprendizagem em contabilidade embasados na Teoria da Assimilação. Os achados da pesquisa podem ser considerados como benefício aos docentes e gestores acadêmicos que queiram utilizar ou incentivar o uso de metodologias ativas no ambiente educacional. A inovação pedagógica requer a formação docente, os resultados desta pesquisa poderão motivar a busca pela capacitação dos professores, com o propósito de contribuir para a qualidade do ensino e melhor desempenho acadêmico dos estudantes.

\section{FUNDAMENTAÇÃO TEÓRICA}

\subsection{Teoria da Assimilação}

A Teoria da Assimilação se liga à corrente teórica cognitivista por especular sobre os mecanismos internos da mente humana durante a aprendizagem. Seus pressupostos iniciais foram descritos pelo psicólogo e médico estadunidense David Paul Ausubel, na edição de 1963 do livro The Psychology of Meaningful Verbal Learning (Ausubel, Novak, \& Hanesian, 1980). Sob a luz dessa teoria, a estrutura cognitiva é composta por conceitos e proposições relevantes e inclusivos que são resultados de aprendizagens significativas anteriores do indivíduo, os quais são denominados subsunçores. Eles surgem por meio da aprendizagem mecânica de conhecimentos ainda inexplorados ou menos conhecidos pelo aprendiz. À medida que o domínio sobre o conteúdo aumenta, os subsunçores se desenvolvem e passam a ter o papel fundamental de facilitar novas aprendizagens (Moreira, 2017).

Como forma de esclarecer os conceitos ligados à teoria ausubeliana, como também evidenciar os diversos tipos de ocorrência da aprendizagem, Ausubel et al. (1980) e Ausubel (2000) propõem diferenciar os seguintes processos: i) aprendizagem significativa ou mecânica; e ii) aprendizagem por recepção ou por descoberta.

A aprendizagem significativa é fruto do processo ativo e interacional (não arbitrário e substantivo) entre os conhecimentos já apropriados pelo aprendiz e um novo conteúdo (Ausubel, 2000). A não arbitrariedade se refere a uma "relação lógica e explícita" que deve haver entre a nova informação e o que já foi aprendido (Präss, 2012, p. 29). Ao tratar da forma substantiva, ela diz respeito à aprendizagem não literal, em que a essência do conteúdo é captada (Präss, 2012). Essa forma de aprendizagem é reforçada, por exemplo, quando ocorre uma forte associação entre um novo conceito mais avançado de Contabilidade e os saberes adquiridos nos anos iniciais do curso, dando maior significado àquilo que está sendo aprendido.

Por outro lado, a aprendizagem mecânica resulta da pouca ou nenhuma interação entre um novo conteúdo e a estrutura cognitiva preexistente do aprendiz (Moreira, 2017) ou quando uma nova informação é adquirida arbitrariamente e por meio de memorização, não tendo, dessa forma, substancialidade e nem flexibilidade para ser expressa de outra maneira (Präss, 2012). Esse tipo de aprendizagem é comum com os alunos de disciplinas introdutórias de Contabilidade, visto que eles recorrem à memorização de novos conceitos por não deterem saberes prévios relacionados que os auxiliem a aprender.

Em uma outra perspectiva, a aprendizagem por recepção é caracterizada pela transmissão de um novo conteúdo ao aluno na forma como ele deve ser aprendido, não envolvendo qualquer busca independente por parte dele, enquanto na aprendizagem pela descoberta, o professor "propõe algumas 'pistas' sobre o conteúdo final", devendo ele ser explorado de forma autônoma pelo aluno antes de ser aprendido (Pontes Neto, 2006, p. 119). 
Ressalta-se que a aprendizagem por recepção é, frequentemente, associada à aprendizagem mecânica. Contudo, Ausubel et al. (1980) não estabelecem distinções dicotômicas entre nenhum tipo de aprendizagem e, sim, uma relação de continuum (contínuo), visto que tanto a aprendizagem por recepção quanto aquela por meio da descoberta podem ser mecânicas ou significativas, a depender da força interacional entre o novo conteúdo e os subsunçores do aprendiz.

Para que a aprendizagem ocorra de maneira significativa, são necessárias três condições: i) que o aprendiz tenha conhecimento preexistente relevante e inclusivo que facilite a aprendizagem do novo conteúdo; ii) que o novo conteúdo seja potencialmente significativo para o aprendiz à luz dos seus conhecimentos e do valor inerente ao material; e iii) que o aprendiz tenha predisposição para aprender de forma significativa (Ausubel et al., 1980; Ausubel; 2000). Em outras palavras, é essencial que o aluno disponha de conhecimentos que facilitem a aprendizagem do novo conteúdo que ele considere relevante, como também que queira relacioná-lo ativamente com seus saberes prévios disponíveis, a fim de aprendê-lo significativamente.

Alguns estudos investigaram a aplicabilidade da Teoria da Assimilação na área de educação contábil. Por meio de um estudo de caso em uma disciplina de Contabilidade Financeira de uma universidade portuguesa (ISCTE Business School), Vendramin (2018) analisou o efeito da aplicação do Método do Caso para a aprendizagem significativa de alunos de graduação. A autora identificou que, no caso examinado, os três fatores para a ocorrência da aprendizagem significativa foram atendidos, visto que: os saberes prévios do aluno e o conteúdo ensinado nas aulas teóricas constituem o conhecimento anterior; os casos tornaram o material potencialmente significativo; e, além disso, parece ser mais provável que os alunos estejam predispostos a aprender com o uso de metodologias ativas (Vendramin, 2018).

Ao examinarem a estrutura de duas disciplinas ligadas à área de custos do curso de Contabilidade (UFRGS) e de Administração (UNIPAMPA), Behr, Souza, Oliveira, Crestani e Schiavi (2018) concluíram que elas estavam em conformidade com a teoria ausubeliana para a condução da aprendizagem significativa dos alunos. As disciplinas contam com um trabalho de campo, em que os alunos devem desenvolver um projeto de uma empresa, bem como avaliar sua viabilidade. Após analisarem o conteúdo dos relatórios desses trabalhos, os autores verificaram seu potencial para promover um aprender significativo, visto que os alunos passam a aplicar seus saberes sobre o conteúdo fora do contexto escolar, o que promove a diferenciação progressiva e a reconciliação integrativa durante a aprendizagem de conceitos contábeis.

Com base nos estudos de Behr et al. (2018) e Vendramim (2018), percebe-se que a criação de ambientes educacionais ativos parecem ser potenciais meios para que os alunos aprendam de maneira significativa uma nova informação. Michael (2006) reforça essa suposição ao confirmar a efetividade das metodologias ativas com base em evidências teóricas do cognitivismo, visto que elas proporcionam aos alunos a oportunidade de experimentarem, buscarem e compartilharem seus saberes de forma prática.

\subsection{Processo de Ensino-Aprendizagem e Metodologias Ativas de Ensino}

Nos cursos de Contabilidade a abordagem tradicional de ensino é predominante, visto que as aulas expositivas são as mais utilizadas nessa área (Gilioli et al., 2016). Sob o enfoque tradicional, as metodologias de ensino são pautadas na transmissão de informações pelo educador e na recepção passiva pelo educando. Essa abordagem valoriza maior variedade e grande quantidade de informações a serem aprendidas pelos alunos (Mizukami, 1986).

Desse modo, mesmo considerando o potencial das metodologias de ensino tradicionais para a difusão de informações, o seu uso exclusivo pode gerar consequências negativas ou até restringir a aprendizagem dos alunos, visto que, após alguns minutos submetidos às aulas expositivas do professor, a capacidade de retenção dos alunos tende a diminuir (Bonwell \& Eison, 1991). Diante disso, faz-se necessário que professores, alunos e gestores acadêmicos pesquisem, discutam e 
experimentem alternativas metodológicas que sejam capazes de melhorar o processo de ensinoaprendizagem dos cursos de Contabilidade (Silva et al., 2014).

Surgem, assim, as metodologias ativas como alternativa às metodologias tradicionais de ensino em sala de aula, como forma de encorajar a maior participação e responsabilidade dos alunos no processo de ensino-aprendizagem (McKeachie, Pintrich, Lin, \& Smith, 1986). As metodologias ativas podem ser entendidas como quaisquer atividades, das mais simples às mais complexas, das quais os alunos participam de forma efetiva enquanto refletem sobre o que estão fazendo, visando promover uma aprendizagem consciente, ao invés de simplesmente transmitir informações (Bonwell \& Eison, 1991).

Dentre os benefícios do uso dos métodos ativos, Brickner e Etter (2008) destacam o maior interesse do aluno pelo conteúdo, como também o aumento da autonomia na própria aprendizagem. Quando os alunos tomam consciência de que são eles os responsáveis por propor as soluções, mesmo diante de situações problemáticas colocadas pelas atividades, sua motivação para aprender de forma autônoma passa a ser estimulada (Berbel, 2011).

Entretanto, para que ocorra a aprendizagem ativa, são demandados esforços, principalmente por parte de quem as aplica, em geral, o professor. Diante disso, Bonwell e Eison (1991) e Loeb (2014) apontam que os obstáculos percebidos pelos professores, ao cogitarem o uso de metodologias ativas, estão relacionados ao conteúdo (é possível abranger todo o tema), aos alunos (eles vão se envolver ou ter reações negativas), às limitações estruturais (o método é adequado ao tamanho da turma) e às metodologias propriamente ditas (os objetivos de ensino podem ser atingidos). Por isso, os autores sugerem que os professores comecem utilizando métodos ativos mais simples para que, aos poucos, ganhem confiança e passem a aplicar métodos mais elaborados, além de que reforcem aos alunos os objetivos educacionais presentes por trás de cada atividade e os desafios que podem ser encontrados durante sua realização.

Esta pesquisa limitou-se a analisar os métodos Storytelling (Contar histórias), Método do Caso e o Trabalho de Campo. A Storytelling ao ser utilizada como uma metodologia de ensino, envolve o relato de um acontecimento fictício ou factual, cujo objetivo é o de estimular a imaginação dos alunos para que se envolvam com o conteúdo e o assimilem por mais tempo (Miley, 2009; Harbin \& Humphrey, 2010). Porém, para que isso ocorra, uma boa estória precisa ter elementos que gerem emoções, além de que o saber a ser transmitido deve ser facilmente captado (Harbin \& Humphrey, 2010), caso contrário, pode prejudicar o ensino-aprendizagem (Marques, Miranda, \& Mamede, 2017).

Embora soe estranho utilizar a arte para ensinar conteúdos ligados à Contabilidade, Miley (2009) rebate esse equívoco, afirmando que a Contabilidade não apenas é, como também exige certa criatividade dos contadores, devido à quantidade de escolhas que eles precisam tomar no dia a dia da profissão. Além disso, o uso da Storytelling no ensino-aprendizagem do referido curso conduz os alunos a refletirem sobre o impacto da Contabilidade na sociedade, bem como sobre a relevância dos saberes contábeis (Miley, 2009).

Os métodos de ensino narrativos, segundo Harbin e Humphrey (2010), desempenham um papel importante no processo de ensinagem, contudo, poucos professores da área de negócios utilizam esse método, possivelmente pelo fato de que o uso de narrativas seja mais coerente com alguns conteúdos ou disciplinas do que outros. No entanto, independentemente da área, há oportunidades para se utilizarem e investigarem as contribuições dessas técnicas (Harbin \& Humphrey, 2010).

Nesse sentido, de acordo com Marques et al. (2017), a Storytelling pode ser utilizada em cursos da área contábil e correlatas quando o objetivo de ensino do professor é criar um ambiente que estimule e oportunize aos alunos: expressarem seu background de experiências; visualizarem o ambiente organizacional em que o profissional contábil está inserido; fazerem análises e tomarem decisões sobre a situação das empresas; e fazerem abstrações e proporem soluções criativas a partir das narrativas.

Dentre os estudos que investigaram o uso do método de ensino da Storytelling em cursos de Contabilidade e de áreas correlatas, Krom e Williams (2011) propuseram que alunos de disciplinas 
de Contabilidade Financeira de duas faculdades estadunidenses criassem diversos tipos de estórias não contábeis que incorporassem os seguintes conceitos: regime de competência contábil; provisão; ativos diferidos; e balancete ajustado. Foi assinalado pelos alunos que a técnica da narrativa torna o conteúdo familiar, incentivando o entusiasmo e a iniciativa dos alunos na consecução das tarefas. Ainda, cerca de $60 \%$ dos alunos consideraram que a Storytelling os ajudou a entender os conceitos importantes da disciplina, além de que 50\% disseram ter gostado desse método como instrumento de avaliação.

Taylor, Marrone, Tayar e Mueller (2018) aplicaram a Storytelling digital aliada a metáforas visuais a alunos do curso de Contabilidade e de Administração. O estudo durou dois semestres e teve a aplicação de testes no início e no final da pesquisa, os quais levaram os autores a identificarem que os alunos, de ambos os cursos, passaram a perceber maior qualidade e compreensão do material didático, bem como a dedicar mais horas de estudo, além de concordarem que gostariam de ter atividades semelhantes.

Considerando o Método do Caso, segundo Roesch (2007), o mesmo pode ser usado como um complemento às aulas expositivas do professor, com o objetivo de desenvolver competências profissionais nos alunos, bem como familiarizá-los com o ambiente organizacional em que se passa a situação-problema.

Abordam-se, nos casos, situações-problemas que dizem respeito a conflitos enfrentados pelos gestores das organizações (reais ou simuladas) que precisam ser analisados e solucionados com propostas viáveis e consistentemente embasadas (Roesch, 2007). Assim, os alunos percebem formas de usar o conteúdo aprendido no ambiente profissional (Valdevino, Brandão, Carneiro, Santos \& Santana, 2017), levando-os a refletirem e a perceberem a aplicabilidade e relevância do assunto para sua formação profissional (McKeachie et al., 1986).

Partindo para os estudos que examinaram o uso da metodologia de ensino Método do Caso no processo de ensino-aprendizagem da área contábil e afins, o estudo de Stewart e Dougherty (1993) objetivou ensinar a Contabilidade de Custos por meio do referido método. Em um quase-experimento com um grupo de controle, o impacto da intervenção foi medido pelo ganho de desempenho em um exame quantitativo, em uma análise do problema e em uma redação. Os resultados indicaram que apenas o ganho de desempenho nas redações pôde ser considerado um efeito do caso analisado, visto que as variações entre os desempenhos nas testagens dos demais exames foram iguais entre os dois grupos.

Em um cenário semelhante, Valdevino et al. (2017) descreveram o uso do Método do Caso no desenvolvimento de habilidades em alunos do curso de administração de uma IES pública cearense. Os achados demonstraram que o uso do caso aperfeiçoou a habilidade de argumentação e comunicação dos alunos, como também sua capacidade gerencial. Além disso, os alunos concordaram que a aplicação de casos em sala de aula tornava o ambiente mais dinâmico.

Sob o enfoque da Taxonomia de Bloom, Costa, Gomes, Braunbeck, \& Santana (2018) analisaram a aplicação do caso Open Safari com alunos da disciplina Teoria da Contabilidade no desenvolvimento de habilidades que auxiliam a aprendizagem das International Financial Reporting Standards. De acordo com os autores, o caso proporcionou, em diferentes graus, o desenvolvimento de habilidades de todos os grupos testados à luz da referida Taxonomia: conhecimento; compreensão; aplicação; análise; síntese; avaliação. $\mathrm{Na}$ percepção dos alunos, o método promoveu o desenvolvimento de habilidades fundamentais ao exercício da profissão contábil, como buscar soluções alternativas para os problemas organizacionais, vivenciar situações em que decisões são tomadas no âmbito das empresas e aperfeiçoar a capacidade de resolver problemas em cenários incertos e com informações faltantes.

As atividades práticas podem ocorrer tanto dentro quanto fora da sala de aula. O Trabalho de Campo parte do princípio da integração ativa do aluno com o meio em que ele está inserido para que ele seja capaz de desenvolver uma percepção criteriosa dos fatos, e integrar seus conhecimentos à sua realidade. De posse de seus saberes experienciais e teóricos, o ideal é que o aluno vivencie a atividade 
como se fosse uma real situação de trabalho, tendo ele a oportunidade de aplicar e reforçar seus conhecimentos específicos por meio de práticas empíricas, o que contribui não apenas para a compreensão do conteúdo, mas também para melhorar as relações entre os próprios alunos e professor-aluno (Tomita, 1999).

O Trabalho de Campo promove uma aprendizagem interdisciplinar e centrada no aluno, cujo objetivo é o de fomentar o hábito de pesquisa, bem como a ação-observação além dos muros universitários, levando a sala de aula para o contexto em estudo (Lopes \& Pontuschka, 2009). Essa transposição leva os alunos a perceberem as diversas dinâmicas do meio profissional em que irão atuar e a se atentarem para a importância de serem profissionais adaptáveis (Anastasiou \& Alves, 2015).

No campo educacional contábil, a falta de experiência com processos reais ou que simulem situações reais pode levar o aluno a ser incapaz ou ter dificuldade de perceber como aplicar os saberes teóricos de Contabilidade vistos em sala de aula. Nesse sentido, as atividades práticas ajudam os alunos, com pouca ou nenhuma experiência profissional, a visualizarem a relevância do conteúdo e a sua aplicação em organizações reais por meio de atividades experienciais vividas no ambiente educacional (Lightbody, 2002).

É aconselhável o uso do Trabalho de Campo nos casos em que o objetivo educacional seja que os alunos identifiquem os desafios que os contadores vivenciam em sua profissão e identifiquem, compreendam e resolvam problemáticas reais com base no conteúdo aprendido em sala de aula ou por meio de pesquisas feitas em fontes externas (Santos, 2017).

É importante destacar que há evidências empíricas dos benefícios do uso dos métodos práticos de ensino para os alunos da área contábil. Lightbody (2002) propôs um método de simulação fabril, de modo que os alunos atuaram, dentro da sala de aula, como se estivessem em setores de uma fábrica de coelhos de papel. A autora evidenciou que o contato imediato com a produção aumentou a compreensão dos alunos sobre o conteúdo de Contabilidade Gerencial e eles se mostraram mais dispostos e aptos a discutirem criticamente a aplicação prática desses saberes.

O estudo de Bremser e White (2000) envolveu a aplicação de uma atividade que simulava a implementação do Balanced Scorecard em organizações reais, o que foi feito com graduandos e pósgraduandos em Contabilidade, matriculados em disciplinas de Contabilidade Gerencial. A experiência dos autores foi avaliada como consistente pelos alunos, os quais justificaram que o projeto ajudou a compreender a estratégia das organizações e a medir seu desempenho. Os graduandos disseram ter desenvolvido suas habilidades de apresentação e de trabalho em equipes.

Por meio de um estudo quase-experimental, Kern (2002) conduziu aulas de Contabilidade Introdutória em uma universidade pública americana, tendo sido experimentados três cenários de ensino de custeios: no primeiro, foram utilizados apenas métodos expositivos; no segundo, a abordagem integrou os métodos expositivos e a resolução de uma atividade prática; e, no terceiro, foram aplicadas somente metodologias ativas e atividades práticas. Os resultados experimentais indicaram que os alunos que participaram do terceiro ambiente obtiveram notas significativamente maiores nos testes de conhecimentos sobre o conteúdo do que aqueles que foram expostos aos modelos baseados em exposição ou mistos. Tais achados fornecem evidências da efetividade do uso de atividades práticas no ensino de custos.

Brickner e Etter (2008) descreveram o uso de diversas metodologias ativas e, dentre as que ocorreram fora da sala de aula, destaca-se a participação de alunos do curso de Contabilidade Introdutória em reuniões de organizações estudantis de negócios e a realização de análise de relatórios anuais das organizações. O estudo sugere que as reuniões de negócios desenvolvem uma melhor compreensão sobre os problemas que impactam a profissão, bem como desenvolvem suas habilidades interpessoais, tornando-os mais motivados, atenciosos e comprometidos em sala de aula.

Percebe-se que a Storytelling, o Método do caso e o Trabalho de campo são métodos de ensino que proporcionam benefícios em comum ao processo de ensino, como também fornecem contribuições específicas ligadas à sua natureza prática. 
Ao recuperar os pressupostos da teoria ausubeliana para as discussões deste trabalho, entendese que o uso de atividades práticas de ensino promove a aprendizagem significativa em virtude de vários fatores. Segundo Ausubel (2000), a atividade prática aumenta a força de dissociabilidade do produto interacional, bem como a sensibilidade do indivíduo de recuperar o novo conceito em uma futura situação de aprendizagem semelhante. Ou seja, quanto mais a nova informação for praticada, menos chance ela tem de ser esquecida. Além disso, caso este conhecimento esteja sofrendo o processo de esquecimento, a prática é capaz de conscientizar o indivíduo dos fatores que causam a assimilação obliteradora, possibilitando que eles sejam mitigados (Ausubel, 2000).

\section{PROCEDIMENTOS METODOLÓGICOS}

Esta pesquisa se caracteriza como descritiva quanto aos seus objetivos. Quanto à abordagem, é mista, visto que associa procedimentos de coleta de dados quantitativos e qualitativos, com o propósito de expandir e aprofundar a compreensão sobre o tema em estudo (Bryman, 2012).

Durante a Etapa Quantitativa, desenvolveu-se o quase-experimento com o objetivo de examinar o uso de metodologias ativas na disciplina de Análise de Custos do curso de Ciências Contábeis. Para isso, ela envolve a coleta de dados mediante a aplicação de questionários, os quais são tratados quantitativamente por meio de análise descritiva e testes de comparações de médias. Na sequência, desenvolve-se a Etapa Qualitativa, em que são realizadas entrevistas de grupos focais com o intuito de colher a percepção dos alunos acerca da aplicação das metodologias ativas. Para interpretar as declarações dos entrevistados, procede-se a técnica da análise de conteúdo.

A população deste estudo é composta por alunos do curso de Ciências Contábeis de uma IES pública mineira, matriculados na disciplina Análise de Custos, no $2^{\circ}$ semestre letivo de 2018. Com relação ao referido curso, o ingresso é semestral e é ofertado em dois turnos: integral e noturno. Ressalta-se que a disciplina é um componente curricular obrigatório do $5^{\circ}$ período, é oferecida, semestralmente, para os dois turnos e não possui pré-requisitos curriculares. Assim, as turmas que constituem a amostra desta pesquisa foram chamadas de: Turma A e Turma B, as amostras variam conforme a aplicação das etapas.

Destaca-se que esta pesquisa foi aprovada pelo Comitê de Ética em Pesquisa com Seres Humanos de uma IES federal mineira, de acordo com o Certificado de Apresentação para Apreciação Ética (CEP) n. 08191219.0.0000.5152.

A pesquisa foi realizada com os dois turnos em sala de aula ao longo de, aproximadamente, dois bimestres e, por isso, todos os alunos matriculados cumpriram a disciplina normalmente. Todavia, seus dados somente foram utilizados mediante aceite constante em Termo de Consentimento Livre e Esclarecido aprovado pelo CEP.

\subsection{Etapa Quantitativa da Pesquisa}

Para entender o delineamento quase-experimental adotado neste estudo é necessário informar as condições da pesquisa experimental, a saber: replicação do tratamento; atribuição aleatória dos grupos que receberão o tratamento; manipulação da variável independente (tratamento); e controle de possíveis fatores que expliquem os efeitos encontrados (Shadish, Cook \& Campbell, 2002; Bryman, 2012). Nesta pesquisa, no entanto, não foi possível atender a todos esses critérios, visto que os participantes, oriundos de salas de aula que mantiveram sua formação populacional original, foram selecionados por conveniência. Isso ocorreu pela impossibilidade de se atribuírem, aleatoriamente, grupos de controle e experimental com os participantes da pesquisa, haja vista que isso causaria transtornos à rotina dos alunos, da professora que se prontificou a participar da pesquisa e da própria instituição. Ademais, por se tratar de um experimento de campo, que ocorre em ambientes naturais, não é pleno o controle de todas as variantes que possam explicar os efeitos encontrados na pesquisa (Bryman, 2012). 
Devido aos motivos mencionados acima, neste estudo foi utilizado o delineamento quaseexperimental com grupo de controle não equivalente com pré-teste e pós-teste. Nesse modelo, ambos os testes são usados para garantir a sua validade metodológica, devido à atribuição dos grupos não ter sido aleatória (Shadish et al., 2002). Além disso, para melhorar a validade desse modelo, invertese a intervenção entre os grupos, de modo que o tratamento passe a ser administrado àquele grupo que, anteriormente, não o havia recebido. Uma vantagem da inversão do tratamento é permitir que nenhum indivíduo seja privado dos benefícios esperados decorrentes de sua aplicação. Porém, caso esses benefícios sejam permanentes, eles podem influenciar os resultados de futuras replicações (Shadish et al., 2002).

O Tratamento Experimental foi aplicado em dois momentos: Primeira e Segunda Etapa. A Primeira Etapa foi constituída de quatro encontros ao longo de, aproximadamente, três semanas. Nesta etapa, o Grupo Experimental (GE) (Turma A) foi composto por 24 alunos e o Grupo de Controle (GC) (Turma B) por 35 alunos, constituindo uma amostra geral de 59 participantes. No primeiro encontro, aplicou-se aos alunos de ambos os grupos o questionário para o levantamento do perfil socioeconômico, acompanhado do Teste de Conhecimentos 1 em caráter de Pré-teste, tendo sido em seguida, iniciada a fase de Tratamento Experimental. Nessa etapa, o GE recebeu a aplicação do Método do Caso "Fábula para adultos", proposto por Bruni e Famá (2012), e da Storytelling "Dona Mafalda", elaborada por Leal (N/P). Os conteúdos abordados nas atividades foram: Custeio por Absorção versus Custeio Variável e Análise de Margem de Contribuição. Essa etapa foi finalizada com a aplicação do Teste de Conhecimentos 1, individual, em caráter de Pós-teste, ao final do quarto encontro, para ambos os grupos.

A Segunda Etapa também foi constituída de quatro encontros. Nesta etapa ocorreu a inversão do Tratamento Experimental entre as turmas. Assim, o GE (Turma B) passou a ser composto por 21 alunos e o GC (Turma A) por 24 alunos, totalizando uma amostra geral de 45 participantes. Nessa etapa, o GE recebeu a aplicação do Método do Caso "Carrocerias Marcondes Ltda.", adaptado do estudo de caso feito por Teixeira, Leal e Miranda (2008), e da Storytelling "Taly Baby", adaptada de Nascimento (2015). Os conteúdos abordados nas atividades foram: Análise da relação custo/volume/lucro e Análise de custos na decisão de preço. No início do primeiro encontro foi aplicado o Teste de Conhecimentos 2 em caráter de Pré-teste para ambos os grupos. A Segunda Etapa foi concluída com a aplicação do Teste de Conhecimentos 2, na modalidade de Pós-teste, a ambos os grupos, no último encontro.

Como mencionado acima, ao longo do período quase-experimental, foram aplicados questionários com o objetivo de identificar o perfil socioeconômico e o desempenho acadêmico dos alunos. O questionário utilizado para traçar o perfil socioeconômico dos alunos da pesquisa é composto por 10 questões categóricas que buscam identificar o gênero, a idade, o estado civil, em que tipo de escola o aluno cursou o ensino médio, se cursou outra graduação, se é repetente na disciplina Análise de Custos, se exerce atividade remunerada e se possui experiência profissional (geral, na área contábil e na área de custos).

Para avaliar a aprendizagem dos participantes, os Testes de Conhecimentos (1 e 2) versam sobre tópicos de Análise de Custos e buscam avaliar o nível de conhecimentos sobre o conteúdo descrito na ementa da disciplina. Os testes são compostos por 12 questões de múltipla escolha ("Concordo Totalmente", "Não Concordo e Nem Discordo", e "Discordo Totalmente"), elaboradas com base em Martins (2010) e Bruni e Famá (2012), visto que tais obras compõem a bibliografia base da disciplina em estudo.

Na sequência, procede-se ao tratamento quantitativo dos dados. Para tanto, verifica-se se os desempenhos dos alunos no Pré-teste são estatisticamente semelhantes no Pós-teste. Caso eles sejam iguais, o desempenho final (Pós-teste) dos alunos não pode ser explicado pela variável explicativa analisada, do contrário, é possível atribuir às metodologias de ensino a variação no desempenho dos alunos. A comparação dos desempenhos foi realizada por meio do teste $t$ de Student pareado uni 
caudal. Nos casos em que os pressupostos do referido teste tenham sido violados, procedeu-se, como alternativa, o uso do teste não paramétrico de Wilcoxon.

\subsection{Ełapa Qualitativa da Pesquisa}

A etapa qualitativa da pesquisa foi realizada após o término da etapa quase-experimental. Nesta fase, a intervenção foi administrada para ambas as turmas, ao longo de três encontros, mediante a aplicação do Trabalho de Campo "Fábrica de sanduíches e salgados", abrangendo todo o conteúdo abordado na etapa quase-experimental.

Os dados foram coletados após o último encontro por meio de duas entrevistas de grupos focais realizadas na sala de aula, compostas por 13 participantes da Turma A e 10 da Turma B. A entrevista com a Turma A teve duração de 44 minutos e com a Turma B, 54 minutos. Para preservar a identidade dos participantes, as declarações dos entrevistados serão indicadas pela letra "P" (participante), seguida por uma numeração sequencial, por exemplo: P1, P2, ..., e P23.

Bryman (2012) define as entrevistas de grupo focal como sendo uma entrevista em conjunto envolvendo entrevistados que tenham presenciado um evento em comum. A mediação foi realizada por uma professora da instituição em estudo, a qual foi convidada por possuir experiência na condução de grupos focais, o que é fundamental para que essa modalidade de entrevista alcance os objetivos esperados. Os pesquisadores participaram como ouvintes, enquanto tomavam notas e registravam as sessões por meio da gravação de áudio, para posterior transcrição e arquivamento em formato digital.

Neste trabalho, recorreu-se à técnica de análise de conteúdo para "obter por procedimentos sistemáticos e objetivos de descrição do conteúdo das mensagens indicadores (quantitativos ou não) que permitam a inferência de conhecimentos relativos às condições de produção/recepção (variáveis inferidas) dessas mensagens" (Bardin, 2011, p. 48). A análise de conteúdo foi feita em quatro etapas: (i) organização da análise; (ii) codificação; (iii) categorização; (iv) inferências (Bardin, 2011).

\section{ANÁLISE DOS RESULTADOS}

\subsection{Resultados da Ełapa Quantitativa da Pesquisa}

Como relatado anteriormente, não foi possível formar grupos de controle e tratamento com base em atribuição aleatória dos alunos. Por isso é importante traçar o perfil dos participantes, a fim verificar a extensão na qual se pode generalizar os resultados da amostra do experimento para uma população, bem como a extensão na qual variáveis pessoais interagem com os efeitos do tratamento.

A Tabela 1 permite delinear o perfil dos alunos que participaram da etapa quase-experimental deste estudo. Frisa-se que na Primeira Etapa o tratamento foi administrado ao GE (Turma A) por meio da aplicação dos métodos de ensino: Storytelling e Método do caso. Enquanto o GC (Turma B) foi submetido às metodologias tradicionais de ensino.

Conforme a Tabela 1, ao comparar o GE com o GC, verifica-se que características como o gênero, o estado civil, o tipo de escola que cursou o ensino médio, o fato de não ter experiência profissional na área de custos e não ser repetente na disciplina de Análise de Custos são proporcionalmente semelhantes entre os grupos, assim como o fato de os participantes estarem fazendo o primeiro curso superior. Por outro lado, observa-se que a idade parece não ser igual entre os grupos, haja vista que o GE é composto, quase que exclusivamente, por alunos de até 21 anos $(91,7 \%)$, enquanto a maioria dos que compõem o GC têm idade superior a 22 anos $(62,9 \%)$. Ao comparar o perfil profissional entre os grupos, nota-se que os alunos do GC estão mais inseridos em atividades profissionais em período integral $(51,4 \%)$ e possuem maior experiência no mercado de trabalho $(82,9 \%)$ e na área contábil $(42,9 \%)$ em relação aos alunos do GE $(12,5 \%, 50 \%$ e $16,7 \%$, respectivamente). 
Tabela 1

Perfil dos Participantes

\begin{tabular}{|c|c|c|c|c|c|c|c|c|}
\hline \multirow{3}{*}{ Variáveis qualitativas } & \multicolumn{4}{|c|}{ Primeira Etapa Experimental } & \multicolumn{4}{|c|}{ Segunda Etapa Experimental } \\
\hline & \multicolumn{2}{|c|}{$\begin{array}{c}\text { GE } \\
(n=24) \\
\end{array}$} & \multicolumn{2}{|c|}{$\begin{array}{c}\text { GC } \\
(n=35)\end{array}$} & \multicolumn{2}{|c|}{$\begin{array}{c}\text { GE } \\
(n=21)\end{array}$} & \multicolumn{2}{|c|}{$\begin{array}{c}\mathrm{GC} \\
(n=24)\end{array}$} \\
\hline & freq. & $\%$ & freq. & $\%$ & freq. & $\%$ & freq. & $\%$ \\
\hline \multicolumn{9}{|c|}{ Ensino médio } \\
\hline Escola Pública & 16 & $66,70 \%$ & 29 & $82,90 \%$ & 18 & $85,70 \%$ & 17 & $70,80 \%$ \\
\hline Escola Privada & 7 & $29,20 \%$ & 5 & $14,30 \%$ & 3 & $14,30 \%$ & 5 & $20,80 \%$ \\
\hline Ambos & 1 & $4,20 \%$ & 1 & $2,90 \%$ & 0 & $0,00 \%$ & 2 & $8,30 \%$ \\
\hline \multicolumn{9}{|c|}{ Outro curso } \\
\hline Não & 19 & $79,20 \%$ & 23 & $65,70 \%$ & 16 & $76,20 \%$ & 17 & $70,80 \%$ \\
\hline Sim, mas abandonei & 5 & $20,80 \%$ & 9 & $25,70 \%$ & 4 & $19,00 \%$ & 6 & $25,00 \%$ \\
\hline Sim, mas não decidi qual fazer & 0 & $0,00 \%$ & 2 & $5,70 \%$ & 1 & $4,80 \%$ & 0 & $0,00 \%$ \\
\hline Sim e já concluí & 0 & $0,00 \%$ & 1 & $2,90 \%$ & 0 & $0,00 \%$ & 1 & $4,20 \%$ \\
\hline \multicolumn{9}{|c|}{ Estado civil } \\
\hline Solteiro & 23 & $95,80 \%$ & 28 & $80,00 \%$ & 16 & $76,20 \%$ & 23 & $95,80 \%$ \\
\hline Casado & 1 & $4,20 \%$ & 4 & $11,40 \%$ & 4 & $19,00 \%$ & 1 & $4,20 \%$ \\
\hline Outro & 0 & $0,00 \%$ & 3 & $8,60 \%$ & 1 & $4,80 \%$ & 0 & $0,00 \%$ \\
\hline \multicolumn{9}{|c|}{ Trabalha } \\
\hline Não & 12 & $50,00 \%$ & 10 & $28,60 \%$ & 8 & $38,10 \%$ & 10 & $41,70 \%$ \\
\hline Eventualmente & 1 & $4,20 \%$ & 0 & $0,00 \%$ & 0 & $0,00 \%$ & 3 & $12,50 \%$ \\
\hline Meio período & 7 & $29,20 \%$ & 2 & $5,70 \%$ & 1 & $4,80 \%$ & 5 & $20,80 \%$ \\
\hline Semi-integral & 1 & $4,20 \%$ & 5 & $14,30 \%$ & 2 & $9,50 \%$ & 1 & $4,20 \%$ \\
\hline Integral & 3 & $12,50 \%$ & 18 & $51,40 \%$ & 10 & $47,60 \%$ & 5 & $20,80 \%$ \\
\hline \multicolumn{9}{|c|}{ Sexo } \\
\hline Masculino & 11 & $45,80 \%$ & 16 & $45,70 \%$ & 11 & $52,40 \%$ & 10 & $41,70 \%$ \\
\hline Feminino & 13 & $54,20 \%$ & 19 & $54,30 \%$ & 10 & $47,60 \%$ & 14 & $58,30 \%$ \\
\hline \multicolumn{9}{|c|}{ Idade } \\
\hline 18 anos & 1 & $4,20 \%$ & 0 & $0,00 \%$ & 0 & $0,00 \%$ & 1 & $4,20 \%$ \\
\hline 19 anos & 2 & $8,30 \%$ & 2 & $5,70 \%$ & 2 & $9,50 \%$ & 3 & $12,50 \%$ \\
\hline 20 anos & 12 & $50,00 \%$ & 6 & $17,10 \%$ & 4 & $19,00 \%$ & 9 & $37,50 \%$ \\
\hline 21 anos & 7 & $29,20 \%$ & 5 & $14,30 \%$ & 3 & $14,30 \%$ & 6 & $25,00 \%$ \\
\hline de 22 a 25 anos & 1 & $4,20 \%$ & 11 & $31,40 \%$ & 5 & $23,80 \%$ & 2 & $8,30 \%$ \\
\hline acima de 25 anos & 1 & $4,20 \%$ & 11 & $31,40 \%$ & 7 & $33,30 \%$ & 3 & $12,50 \%$ \\
\hline \multicolumn{9}{|c|}{ Repetente na disciplina } \\
\hline Sim & 1 & $4,20 \%$ & 3 & $8,60 \%$ & 1 & $4,80 \%$ & 1 & $4,20 \%$ \\
\hline Não & 23 & $95,80 \%$ & 32 & $91,40 \%$ & 20 & $95,20 \%$ & 23 & $95,80 \%$ \\
\hline \multicolumn{9}{|c|}{ Experiência profissional } \\
\hline Sim & 12 & $50,00 \%$ & 29 & $82,90 \%$ & 18 & $85,70 \%$ & 13 & $54,20 \%$ \\
\hline Não & 12 & $50,00 \%$ & 6 & $17,10 \%$ & 3 & $14,30 \%$ & 11 & $45,80 \%$ \\
\hline \multicolumn{9}{|c|}{ Experiência com Contabilidade } \\
\hline Sim & 4 & $16,70 \%$ & 15 & $42,90 \%$ & 11 & $52,40 \%$ & 1 & $4,20 \%$ \\
\hline Não & 20 & $83,30 \%$ & 20 & $57,10 \%$ & 10 & $47,60 \%$ & 23 & $95,80 \%$ \\
\hline \multicolumn{9}{|c|}{ Experiência com Custos } \\
\hline Não & 24 & $100,00 \%$ & 35 & $100,00 \%$ & 21 & $100,00 \%$ & 24 & $100,00 \%$ \\
\hline
\end{tabular}

Fonte: Dados da pesquisa.

Na Segunda Etapa houve a inversão do tratamento entre as turmas, de modo que a Turma B passou a ser o GE e a Turma $\mathrm{A}$ foi submetida às condições de controle. O tratamento foi aplicado ao GE por meio, novamente, do Método do Caso e da Storytelling, enquanto no GC adotaram-se as condições de ensino tidas como tradicionais. Ao alternar a variável analisada entre os grupos em estudo, foi assegurado que o tratamento foi completamente retirado do grupo que, originalmente, o havia recebido. Além disso, uma desvantagem inerente a essa inversão é que os efeitos da etapa 
anterior podem ser permanentes e, por isso, afetar os resultados dessa nova replicação, constituindose uma limitação do estudo (Shadish et al., 2002).

Embora a composição e o tamanho da amostra sejam diferentes entre a Primeira e a Segunda Etapa, verifica-se similaridades entre elas. Assim como na etapa anterior, as diferenças (idade, inserção profissional, experiência no mercado de trabalho e na área contábil) e as semelhanças (gênero, tipo de escola que cursou o ensino médio, o fato de estar cursando a primeira graduação, não ter experiência profissional e não ser repetente na disciplina de Análise de Custos) permanecem as mesmas entre os grupos.

Para examinar se o uso de metodologias ativas contribui para uma aprendizagem significativa, apresenta-se na Tabela 2, inicialmente, o desempenho médio obtido pelos alunos na Primeira Etapa nos Testes de Conhecimentos 1 (Pré-teste e Pós-teste), como também seus escores médios de variação (desempenho no Pós-teste menos o desempenho no Pré-teste).

Tabela 2

Primeira Etapa: Desempenhos dos participantes

\begin{tabular}{cccc|ccc}
\hline \multirow{2}{*}{ Desempenhos } & \multicolumn{3}{c|}{ GE $(\mathbf{n}=\mathbf{2 4})$} & \multicolumn{3}{c}{ GC $(\mathbf{n}=\mathbf{3 5})$} \\
\cline { 2 - 7 } & Pré-teste & Pós-teste & Variação & Pré-teste & Pós-teste & Variação \\
\hline \multirow{2}{*}{ Médio } & 0,44 & 0,63 & $-0,18$ & 0,36 & 0,58 & $-0,21$ \\
DP & 0,10 & 0,11 & 0,18 & 0,10 & 0,15 & 0,17 \\
\hline
\end{tabular}

Legenda: Os desempenhos variam entre 0 (0\% de acertos) e 1 (100\% de acertos).

Fonte: Dados da pesquisa.

Ao observar a Tabela 2, percebe-se que, embora o GE tenha tido maior desempenho nos testes inicial e final que o GC, o escore de variação do GC foi superior. Assim, para testar se as variações do desempenho foram estatisticamente significativas ao final desta etapa, aplicou-se o teste $t$ uni caudal - ou alternativa não paramétrica - com o propósito de avaliar se os grupos obtiveram ganho de performance significativo. Para tanto, formula-se a hipótese nula $\left(\mathbf{H}_{0}\right)$ do referido teste, a qual assume que a média de notas dos alunos no Pré-teste não é menor que a do Pós-teste; a hipótese alternativa $\left(\mathbf{H}_{1}\right)$ declara que a média de notas dos alunos no Pré-teste é menor que a do Pós-teste. Os resultados do teste de hipótese são apresentados na Tabela 3.

Tabela 3

Primeira Etapa: Comparação entre os escores dos alunos no Pré-teste e Pós-teste

\begin{tabular}{ccccccc}
\hline Grupo & Desempenhos & n & Média & DP & $\boldsymbol{t}$ & $\boldsymbol{p}$ (uni caudal) \\
\hline \multirow{2}{*}{ GE } & Pré-teste & 24 & 0,44 & 0,10 & $-5,08$ & 0,00 \\
& Pós-teste & 24 & 0,63 & 0,11 & & $\boldsymbol{p}$ (uni caudal) \\
\hline \multirow{2}{*}{ Grupo } & Desempenhos & $\mathbf{n}$ & Média & DP & $\boldsymbol{z}$ & 0,00 \\
\multirow{2}{*}{ GC } & Pré-teste & 35 & 0,36 & 0,10 & $-4,70$ & 0,15 \\
& Pós-teste & 35 & 0,58 & & \\
\hline
\end{tabular}

Fonte: Dados da pesquisa.

Como foi observado na análise descritiva dos Testes de Conhecimentos apresentada na Tabela 2, o teste de hipóteses confirmou que houve variação significativa no desempenho dos alunos entre as duas etapas de testagem, visto que a hipótese nula $\left(\mathbf{H}_{0}\right)$ foi rejeitada para ambos os grupos. Portanto, foram encontradas evidências de que o uso do Método do Caso e da Storytelling podem ter contribuído para a aprendizagem significativa dos alunos da disciplina de Análise de Custos, assim como as metodologias tradicionais de ensino. Esse resultado corrobora Kern (2002), cujo estudo evidenciou um ganho de desempenho significativo de alunos que aprenderam em ambientes ativos. Por outro lado, Stewart e Dougherty (1993) demonstraram que o uso do Método do Caso na disciplina de Contabilidade de Custos não melhora o desempenho dos alunos em exames quantitativos, embora os autores tenham assinalado que o método seja efetivo em exames qualitativos. 
Dando continuidade à análise, apresenta-se na Tabela 4 o desempenho alcançado pelos alunos na Segunda Etapa nos Testes de Conhecimentos 2 (Pré-teste e Pós-teste), bem como seus escores de variação.

Tabela 4

Segunda Etapa: Desempenhos dos participantes

\begin{tabular}{cccc|ccc}
\hline \multirow{2}{*}{ Desempenhos } & \multicolumn{3}{c|}{ GE $(\mathbf{n}=\mathbf{2 1})$} & \multicolumn{3}{c}{ GC $(\mathbf{n}=\mathbf{2 4})$} \\
\cline { 2 - 7 } & Pré-teste & Pós-teste & Variação & Pré-teste & Pós-teste & Variação \\
\hline Média & 0,51 & 0,69 & $-0,18$ & 0,61 & 0,76 & $-0,15$ \\
DP & 0,13 & 0,16 & 0,16 & 0,16 & 0,13 & 0,19 \\
\hline
\end{tabular}

Legenda: Os desempenhos variam entre 0 ( $0 \%$ de acertos) e 1 ( $100 \%$ de acertos).

Fonte: Dados da pesquisa.

Consoante a Tabela 4, é visto que os alunos do GC apresentam desempenhos inicial e final superiores aos do GE. Ao analisar o escore de variação, o GE apresentou uma média ligeiramente maior que o GC. Para avaliar se o ganho de desempenho dos grupos foi estatisticamente significativo ao final desta etapa, comparou-se os escores dos alunos no Pré-teste e Pós-teste mediante aplicação do teste pareado uni caudal de comparação de médias. Os resultados dos testes de hipóteses estão demonstrados na Tabela 5.

Tabela 5

Segunda Etapa: Comparação entre os escores dos alunos no Pré-teste e Pós-teste

\begin{tabular}{ccccccc}
\hline Grupo & Desempenhos & n & Média & DP & $\boldsymbol{t}$ & $\boldsymbol{P}$ (uni caudal) \\
\hline \multirow{2}{*}{ GE } & Pré-teste & 21 & 0,51 & 0,13 & $-3,18$ & 0,00 \\
& Pós-teste & 21 & 0,69 & 0,16 & $\boldsymbol{z}$ & $\boldsymbol{p}$ (uni caudal) \\
\hline \multirow{2}{*}{ Grupo } & Desempenhos & n & Média & DP & $-3,89$ & 0,00 \\
\hline \multirow{2}{*}{ GC } & Pré-teste & 24 & 0,61 & 0,16 & 0,13 & \\
& Pós-teste & 24 & 0,76 & & \\
\hline
\end{tabular}

Fonte: Dados da pesquisa.

Com base na Tabela 5, a hipótese nula $\left(\mathbf{H}_{0}\right)$ foi rejeitada para ambos os grupos. A rejeição da hipótese para o GE é um indicativo de que o uso das metodologias ativas tem efeito significativo na aprendizagem dos alunos. Tais resultados corroboram aqueles encontrados na Primeira Etapa, bem como os achados de Kern (2002).

Para Ausubel et al. (1980) e Ausubel (2000), conhecer um conceito ou proposição envolve o domínio de significados claros, precisos, diferenciados e transferíveis e, em virtude disso, nem sempre é fácil para o professor identificar a aprendizagem significativa da matéria pelo aluno. Segundo Ausubel (2000), se o objetivo do professor for que o estudante aprenda significativamente o conteúdo e identificar tal aprendizagem, é necessário que o processo de avaliação seja apresentado de uma maneira diferente e não literal, evitando a possibilidade de memorização mecânica das informações ou fórmulas importantes. Logo, para assegurar confiabilidade à avaliação da aprendizagem dos alunos que participaram deste estudo, ressalta-se que os Testes de Conhecimentos, provavelmente, não conduziram os alunos a aprenderem e a exporem seus saberes de maneira mecânica, haja vista que os testes não foram previamente agendados, não eram avaliativos, além de que não foram devolvidos aos alunos, nem corrigidos entre os períodos de testagem.

Em virtude do que foi dito no parágrafo anterior, ao serem examinados, os alunos lançaram mão de conhecimentos significativamente aprendidos, disponíveis em sua estrutura cognitiva, evitando que eles recorressem à memorização mecânica do conteúdo na véspera do exame. Infere-se, portanto, que o aumento do escore dos alunos dos GEs pode ser considerado fruto de um processo de aprendizagem significativa. 
Em síntese, considerando a variação de desempenho acadêmico dos alunos que participaram das etapas quantitativas deste estudo, verifica-se que estatisticamente a aprendizagem significativa é fruto de ambos os ambientes de ensino-aprendizagem, independente do uso de metodologias ativas ou tradicionais.

\subsection{Resultados da Etapa Qualitativa da Pesquisa}

Para ampliar e aprofundar os resultados da etapa quantitativa deste estudo e atingir o objetivo de analisar a contribuição de metodologias ativas para uma aprendizagem significativa na disciplina de Análise de Custos do curso de Ciências Contábeis, esta seção apresenta o tratamento qualitativo das declarações obtidas por meio das entrevistas de grupos focais.

O conteúdo dos relatos é fortemente marcado por trechos que revelam traços de aprendizagem por descoberta, em que os alunos devem buscar, de forma autônoma, pelo conteúdo ou por informações que os auxiliem a melhor aprendê-lo. Como consequência dessa busca, a postura ativa aparece nas declarações que demonstram proatividade e habilidade de pesquisar (Bremser \& White, 2000; Brickner \& Etter, 2008), como também motivação e autonomia para aprender (Berbel, 2011; Paiva et al., 2016). A seguir, são resgatados os relatos que originaram essa interpretação.

Então esse trabalho permitiu muito isso. Porque a gente saiu da nossa comodidade e a gente teve que correr atrás para conseguir chegar no resultado, e mostrar como a gente chegou e se aquele resultado realmente foi bom. Nossa, compensou muito (P19).

No geral, no nosso grupo possibilitou para todos foi a [habilidade de] pesquisa. A gente teve que pesquisar diferentes formas, materiais anteriores para poder conseguir fazer os trabalhos. Eu acho que a pesquisa, a vontade de buscar (P20).

Eu acho que essas metodologias ativas elas fazem com que a gente vá atrás de informações, além do que a gente vê em sala de aula... discute com os colegas. Então acho que é legal para o aprendizado da gente. [...] (P14).

O uso de conhecimentos anteriores também pôde ser identificado nas declarações dos participantes. Foi observado que os saberes que haviam sido adquiridos até então facilitaram a aprendizagem do novo conteúdo, ao mesmo tempo que os que haviam sido esquecidos puderam ser reaprendidos ou reforçados, devido ao efeito residual da aprendizagem significativa (Pontes Neto, 2006; Moreira, 2017). Resgatam-se, abaixo, as declarações que sustentam essa análise.

Sim, [foram necessários conhecimentos de Contabilidade] de Custos 1, rateio, a utilização dos rateios, tipos de custeio. [...] (P03).

Eu acho que trouxe, que retomou assuntos básicos, como 'o que é custo direto, custo indireto?'. Pois na teoria parece muito óbvio, mas quando vamos para o Trabalho de campo, na prática, você fica, 'será que isso aqui é variável, fixo, depende da unidade?' (P04).

Houve ainda o uso de saberes provenientes de aprendizagens significativas em outras áreas do conhecimento ou que não estivessem somente relacionados ao domínio cognitivo de um saber (Diesel et al., 2017). Nesse sentido, percebe-se a importância da experiência profissional no mercado de trabalho, como autônomo e em empresas juniores, como sendo algo que reflete no comportamento e na percepção dos alunos sobre as problemáticas enfrentadas no Trabalho de Campo. Por exemplo, o participante P01 menciona que a apresentação oral não foi um problema para a equipe, pois ele e o outro componente "já trabalha[m] e já trabalhou[aram] com atendimento ao cliente. Essas coisas a gente já tem mais desenvolvimento”. Em complemento, os entrevistados P06 e P16 relatam que:

Na maioria das vezes que eu já vi ou enfrentei [algum desafio] na minha empresa, não é aquilo, é totalmente diferente. [...] (P06). 
No nosso grupo, por conta de eu participar muito da Empresa Júnior, participar de vários eventos, e ter muitos eventos, a gente conversa sobre a liderança. E nosso grupo aconteceu isso de uma maneira muito clara, acabou que eu fiquei na liderança de repassar as tarefas e o time acabou trabalhando em equipe $[\ldots](\mathrm{P} 16)$.

Quanto ao conteúdo da disciplina, Ausubel et al. (1980) explicam que ele depende de dois fatores para ser considerado potencialmente significativo, sendo um relacionado à sua própria natureza e outro ligado à estrutura cognitiva do aprendiz. Em síntese, o conteúdo é considerado significativo quando representa uma interpretação cultural da sociedade (currículo) (Ausubel, 2000) ou quando sua aplicabilidade é percebida pelo aprendiz (Vendramin, 2018). Dessa forma, ao analisar os relatos dos entrevistados é observado que o uso das metodologias ativas foi capaz de tornar o conteúdo da disciplina de Análise de Custos significante, visto que sua importância para a profissão passou a ser notada, assim como sua aplicabilidade passou a ser percebida, o que corrobora Vendramin (2018). Os relatos abaixo confirmam essa interpretação.

É mais fácil procurar na prática, você meio que vê uma finalidade para aquilo. Você não fica só na calculadora fazendo conta e jogar [...] E acaba que se for numa questão que você erra, você nem dá tanta moral. Mas se você falar 'nossa, isso aqui pode servir para mim daqui uns dias', por ser algo mais prático (P23).

Acrescentando sobre o último Trabalho [de campo] a prática ser uma coisa alimentar fez a gente sair do nosso lugar. [...] daí a gente passa a enxergar aonde a nossa profissão está, ali escondidinha (P18).

No trabalho, a gente vê como que é feito os cálculos de todos os custos e tudo mais. Eu pensava que era de uma forma totalmente diferente [...] (P06).

As falas dos entrevistados P17 e P15, descritas na sequência, demonstram que o Trabalho de Campo possibilitou atingir o objetivo proposto pela disciplina, tendo em vista que ajudou os alunos a compreenderem as estratégias das organizações e a terem um posicionamento questionador sobre aspectos ligados à temática custos, como a formação do preço de venda e análise de custos dos produtos. Resultados semelhantes foram descritos por Bremser e White (2000), Lightbody (2002) e Brickner e Etter (2008).

[...] A gente tem que analisar mercado, a gente tem que analisar os concorrentes, os que tem ali em volta, a gente tem que considerar o valor do tributo também que vai ser cobrado em cima do nosso produto [...] (P17).

[...] Mas hoje em dia a gente pensa 'porque ele tá fazendo o preço mais barato? porque os produtos que ele está comprando é mais barato? porque os produtos que ele tá usando não é de qualidade?'. Isso foi possível a partir desse Trabalho [de campo] [...] (P15).

De acordo com os relatos resgatados abaixo, o processo de construção do Trabalho de Campo parece permitir que os alunos aprendam melhor o conteúdo, que se sintam mais bem preparados para aplicá-lo e que consigam superar as dificuldades em aprendê-lo. Essa evidência corrobora Michael (2006), que apontou que a natureza aplicada das metodologias ativas é o que valida sua efetividade no processo de assimilação e construção de novos significados. Além disso, estudos anteriores também demonstraram a efetividade dessas metodologias para o ensino de matérias consideradas importantes para o curso (Krom \& Williams, 2011) ou difíceis de serem aprendidas.

[...] Aqui no nosso curso a gente fica muito na sala de aula, muito na teoria, na teoria. [...] não que a gente não fixe aquela matéria, mas quando você vê na prática como que funciona, como que chega no resultado realmente, é muito mais interessante. Parece que fixa mais na nossa cabeça (P19). 
Agora fez mais sentido [referindo-se ao conteúdo da disciplina] [...] (P08).

[...] Porque eu tenho uma dificuldade muito grande com custos. [...]. Mas (agora está) muito melhor a minha nota [com a aplicação das metodologias ativas] (P17).

Perante o que foi discutido nesta seção, é possível inferir que a inserção das metodologias ativas na disciplina de Análise de Custos cria condições para a ocorrência da aprendizagem significativa do conteúdo. $\mathrm{Na}$ análise das declarações, percebe-se que com a intervenção, tanto a postura ativa dos alunos quanto a sua predisposição para aprender foi incentivada; o conteúdo da disciplina passou a ter significado e ser significante para os alunos; não só demandou, como também reforçou, na resolução das atividades, conhecimentos previamente aprendidos por eles; e a aprendizagem parece ter sido ativa e significativa.

À luz da Teoria da Assimilação, a ação de aprender pode ser compreendida como um processo em que o indivíduo adquire novos conhecimentos, que passam a estar disponíveis em sua estrutura cognitiva para serem futuramente resgatados e utilizados. A predisposição do indivíduo em aprender, as estratégias utilizadas para efetivar esse processo, os saberes disponíveis relacionados ao conteúdo a ser aprendido, e a significância do material em estudo são fatores determinantes do grau de estabilidade, clareza e discriminação do produto final do processo de aprendizagem (Ausubel, 2000).

Em suma, o uso de metodologias ativas na disciplina de Análise de Custos do curso de Ciências Contábeis de uma IES pública mineira contribui para que o aprendizado seja significativo, e o tratamento quantitativo dos resultados dos Testes de Conhecimentos revelou um ganho de desempenho estatisticamente significativo dos alunos submetidos às metodologias ativas em relação aos alunos dos GCs. Esse achado sinaliza que, após terem recebido o conteúdo da disciplina em um ambiente que focou o uso de métodos ativos de ensino, há indícios de que os alunos aprenderam significativamente.

$\mathrm{Na}$ busca por compreender melhor o resultado mencionado acima, o tratamento qualitativo suscitou a percepção dos alunos acerca do uso das metodologias ativas. A partir da perspectiva deles, foi possível identificar que as condições para a ocorrência da aprendizagem significativa foram alcançadas, o que justifica e condiz com o aumento estatisticamente significativo de seus desempenhos acadêmicos.

\section{CONSIDERAÇÕES FINAIS}

A análise de custos é, dentro das Ciências Contábeis, da Gestão Organizacional e da Gestão Pública, uma temática que chama a atenção devido às transformações das organizações nas últimas décadas, principalmente, devido ao ambiente competitivo. Em virtude disso, o mercado de trabalho também passou a exigir mais de profissionais que atuam nessa área, justificando a atenção dada a essa temática nos cursos superiores e nos programas de pós-graduação em Contabilidade.

Nesse sentido, este trabalho foi desenvolvido com o propósito geral de analisar a contribuição de metodologias ativas para uma aprendizagem significativa na disciplina de Análise de Custos do curso de Ciências Contábeis. Corroborando o estudo de Kern (2002), ambas as etapas experimentais deste estudo demonstraram, por meio de testes de hipóteses, que houve aumento significativo do desempenho acadêmico dos alunos dos GEs nos Testes de Conhecimentos. Esse achado permite inferir que, estatisticamente, o uso de metodologias ativas contribui significativamente para a aprendizagem dos alunos, mantendo o nível de desempenho acadêmico dos ambientes educacionais em que foram aplicadas as metodologias tradicionais.

Com base nos relatos dos participantes das entrevistas de grupo focal, também foi possível analisar os efeitos do uso dos métodos ativos de ensino, essencialmente no que tange à criação de condições para a ocorrência da aprendizagem significativa. Em síntese, dentre os pontos mencionados pelos entrevistados, destacam-se os seguintes efeitos decorrentes da aplicação das metodologias 
ativas: uso de conhecimentos anteriores disponíveis relacionados à matéria a ser aprendida; conteúdo passou a ser significativo, e a ter conexão com a realidade vivida pelos alunos; disposição para aprender a aprender; e postura ativa na execução das atividades.

Considerando o que foi dito isso nos parágrafos anteriores, as condições fundamentais (conhecimento prévio disponível; conteúdo potencialmente significativo e relacionável à estrutura cognitiva do aprendiz; disposição em aprender de maneira substantiva e não arbitrária) que devem ser criadas para que o processo de aprender aconteça (Ausubel et al., 1980; Ausubel, 2000) parecem ter sido atingidas quando usadas as metodologias ativas durante a transmissão do conteúdo da disciplina de Análise de Custos

Diante das atuais demandas do mercado de trabalho dos contadores, o fruto do aprender significativo parece ser o que mais se aproxima desse ideal, haja vista que o aprendiz se torna cada vez mais capaz de aprender a aprender, devido aos conceitos subsunçores disponíveis e estabelecidos em sua estrutura cognitiva (Ausubel, 2000). Como consequência disso, o aluno se torna capaz de buscar sua própria evolução ao longo da sua carreira profissional, estando preparado para enfrentar os desafios da (inconstante) profissão contábil.

Dentre as implicações deste trabalho, destaca-se a investigação, bem como a identificação de metodologias de ensino que oferecem melhorias ao processo de ensino-aprendizagem da disciplina Análise de Custos. Este estudo também fornece informações para professores e gestores acadêmicos sobre o uso de metodologias ativas no ambiente educacional, como: suporte teórico-científico; descrição detalhada das etapas de aplicação; e discussão sobre as possíveis contribuições que podem ser esperadas em uma replicação.

Compreende-se que o presente estudo possui delimitações, bem como limitações, e por essa razão são formuladas sugestões para pesquisas futuras. Recomenda-se que a população seja estendida e que integre alunos de outros cursos de áreas correlatas à Contabilidade. Alinhado a isso, sugere-se que atividades ativas passem a ser interdisciplinares, envolvendo não só o conteúdo de outras disciplinas, como também a participação de outros professores. Por fim, sugere-se que outras variáveis e teorias ligadas ao processo de aprender sejam analisadas em trabalhos que investiguem as metodologias ativas de ensino.

Cientes de que neste estudo foi utilizado uma metodologia de pesquisa quase-experimental, em que não foi possível assegurar a validade metodológica de um modelo puramente experimental, destacam-se, na sequência, fatores limitantes que podem afetar a generalização dos resultados encontrados neste estudo.

O quase-experimento foi realizado com duas turmas que estavam matriculadas na mesma disciplina de uma mesma IES. Dessa forma, aspectos relacionados ao tempo e ao ambiente podem ser considerados semelhantes para elas. Ainda assim, os efeitos percebidos podem ser decorrentes das caraterísticas dos grupos pesquisados, haja vista que o GC da primeira etapa que passou a ser o GE na segunda etapa, teve uma melhor variação de desempenho nas duas etapas.

$\mathrm{O}$ fato de as metodologias ativas serem consideradas novidades, por si só, não pode ser responsável pelo melhor rendimento dos participantes. Esse efeito pode ameaçar os resultados observados que dizem respeito à Storytelling, visto que os alunos mencionaram nunca ter tido contato com esse tipo de metodologia ativa. Contudo, relataram já ter tido experiência com o Método do Caso, podendo balancear essa ameaça.

Por fim, os resultados desta pesquisa também podem ter sido ameaçados pela aplicação de múltiplos tratamentos ao longo das etapas experimentais, uma vez que a Storytelling e o Método do Caso são aplicados neste período. Entretanto, ainda que aplicados separadamente, o objetivo geral desta pesquisa é verificar se o uso de metodologias ativas contribui para a aprendizagem significativa dos alunos.

\section{REFERÊNCIAS}


Anastasiou, L. G. C., \& Alves, L. P. (2015). Estratégias de ensinagem. In: Anastasiou, L. G., C., \& Alves, L. P. (Org.). Processos de ensinagem na universidade: Pressupostos para as estratégias de trabalho em aula (10a ed., pp. 75-107). Joinville: Univille.

Ausubel, D. P. (2000). The acquisition and retention of knowledge: A cognitive view. Dordrecht: Kluwer Academic Publishers. doi.org/10.1007/978-94-015-9454-7.

Ausubel, D. P., Novak, J. D., \& Hanesian, H. (1980). Psicologia educacional (2a ed.). Rio de Janeiro: Interamericana.

Bardin, L. (2011). Análise de conteúdo (4a ed.). Lisboa: Edições70.

Behr, A., Souza, A. R. L., Oliveira, C., Crestani, J. S., \& Schiavi, G. S. (2018). Aprendizagem significativa no ensino de custos. Custos e @ gronegócio on line, 14(2), 1-451. doi.org/10.1590/s010365132001000100006.

Berbel, N. A. N. (2011). As metodologias ativas e a promoção da autonomia de estudantes. Semina: Ciências Sociais e Humanas, 32(1), 25-40. doi.org/10.5433/1679-0383.2011v32n1p25.

Bonwell, C. C., \& Eison, J. A. (1991). Active learning: Creating excitement in the classroom. Washignton: ASHE-ERIC Higher Education Reports.

Bremser, W. G., \& White, L. F. (2000). An experimental approach to learning about balanced scorecard. Journal of Accounting Education, 18(3), 241-255. doi.org/10.1016/S0748-5751(00)00016-6.

Brickner, D. R., \& Etter, E. R. (2008). Strategies for promoting active learning in a principles of accounting course. Academy of Educational Leadership Proceedings, 12(2), 87-94. Recuperado de: http://bit.ly/2K4ynWc.

Bruni, A. L., \& Famá, R. (2012). Gestão de custos e formação de preços: Com aplicações na calculadora HP 12C e Excel (6a ed.). São Paulo: Atlas.

Bryman, A. (2012). Social research methods (4th ed.). New York: Oxford University Press.

Costa, P. S., Gomes, G. S., Braunbeck, G. O., \& Santana, M. E. G. (2018). A Safari in Brazil: evidence regarding the Framework-Based Approach to Teaching. Revista Contabilidade \& Finanças, 29(76), 129-147. doi.org/10.1590/1808-057x201804760.

Diesel, A., Baldez, A. L. S., \& Martins, S. N. (2017). Os princípios das metodologias ativas de ensino: uma abordagem teórica. Revista Thema, 14(1), 268-288. doi.org/10.15536/thema.14.2017.268-288.404.

Gilioli, A., Cassaro, M. C. A., Santos, F. A., Amaral, P. F., Cardoso, R. L., \& Benedicto, G. C. (2016). Ensino-aprendizagem na área da educação contábil: uma investigação teórico-empírica. Journal on Innovation and Sustainability, 7(3), 3-28. doi.org/10.24212/2179-3565.2016v7i3p55-72.

Harbin, J., \& Humphrey, P. (2010). Teaching management by telling stories. Academy of Educational Leadership Proceedings, 14(1), 99-106. Recuperado de: http://bit.ly/31adYEe.

Kern, B. B. (2002). Enhancing accounting students' problem-solving skills: The use of a hands-on conceptual model in an active learning environment. Accounting Education, 11(3), 235-256. doi.org/10.1080/09639280210141680.

Krom, C. L., \& Williams, S. V. (2011). Tell me a story: Using creative writing in introductory accounting courses to enhance and assess student learning. Journal of Accounting Education, 29(4), 234-249. doi.org/10.1016/j.jaccedu.2012.06.003.

Laffin, M. (2015). Ensinar conceitos em ciências contábeis. Revista Contemporânea de Contabilidade, 12(25), 47-66. doi.org/10.5007/2175-8069.2015v12n25p47.

Lightbody, M. (2002). Teaching Note Playing factory: Active-based learning in cost and management accounting. Accounting Education, 6(3), 255-262. doi.org/10.1080/096392897331488.

Loeb, S. E. (2014). Active learning: An advantageous yet challenging approach to accounting ethics instruction. Journal of Business Ethics, 127(1), 221-230. doi.org/10.1007/s10551-013-2027-1.

Lopes, C. S., \& Pontuschka, N. N. (2009). Estudo do meio: Teoria e prática. Geografia, 18(2), 173-191. doi.org/10.5433/2447-1747.2009v18n2p173.

Marques, A. V. C., Miranda, G. J., \& Mamede, S. P. N. (2017). Storytelling: Aprendizado de longo prazo. In: Leal, E. A., Miranda, G. J., \& Casa Nova, S. P. C. (Org.). Revolucionando a sala de aula: Como envolver o estudante aplicando as técnicas de metodologias ativas de aprendizagem (pp. 169-185). São Paulo: Atlas.

Martins, E. (2010). Contabilidade de custos (10a ed.). São Paulo, SP: Atlas.

McKeachie, W. J., Pintrich, P. R., Lin, Y., \& Smith, D. A. (1986). Teaching and learning in the college classroom: A review of the research literature. Michigan: University of Michigan Press. 
Michael, J. (2006). Where's the evidence that active learning works? Advances in Physiology Education, 30(4), 159-167. doi.org/10.1152/advan.00053.2006.

Miley, F. (2009). The storytelling project: Innovating to engage students in their learning. Higher Education Research \& Development, 28(4), 357-369. doi.org/10.1080/07294360903046892.

Mitre, S. M., Siqueira-Batista, R., Girardi-De-Mendonça, J. M., Morais-Pinto, N. M., Meirelles, C. A. B., Pinto-Porto, C., Moreira, T., \& Hoffmann, L. M. A. (2008). Metodologias ativas de ensinoaprendizagem na formação profissional em saúde: Debates atuais. Ciência \& Saúde Coletiva, 13, 2133-2144. doi.org/10.1590/S1413-81232008000900018.

Mizukami, M. G. N. (1986). Ensino: As abordagens do processo. São Paulo: E.P.U.

Moreira, M. A. (2017). Teorias de aprendizagem (2a ed.). São Paulo: E.P.U.

Nascimento, R. M. (2015). Taly Baby: O preço de ser popular. ESPM.

Paiva, M. R. F., Parente, J. R. F., Brandão, I. R., \& Queiroz, A. H. B. (2016). Metodologias ativas de ensinoaprendizagem: Revisão integrativa. SANARE, 15(2), 45-153. Recuperado de: http://bit.ly/31L2TK5.

Pontes Neto, J. A. S. (2006). Teoria da aprendizagem significativa de David Ausubel: Perguntas e respostas. Série-Estudos - Periódico do Mestrado em Educação da UCDB, 21, 117-130. doi.org/10.20435/serieestudos.v0i21.296.

Präss, A. R. (2012). Teorias de aprendizagem. Porto Alegre: ScriniaLibris.com.

Roesch, S. M. A. Casos de ensino em Administração: Notas sobre a construção de casos para ensino. Revista de Administração Contemporânea, 11(2), 213-234. doi.org/10.1590/S1415-65552007000200012.

Santos, N. A. (2017). Prática de campo: Desenvolvendo uma atitude científica nos estudantes. In: Leal, E. A., Miranda, G. J., \& Casa Nova, S. P. C. (Org.). Revolucionando a sala de aula: como envolver o estudante aplicando as técnicas de metodologias ativas de aprendizagem (pp. 202-213). São Paulo: Atlas.

Shadish, W. R., Cook, T. D., \& Campbell, D. T. (2002). Experimental and quasi-experimental designs for generalized causal inference. Belmont: Wadsworth/Cengage Learning.

Silva, U. B., Santos, E. B., Cordeiro Filho, J. B., \& Bruni, A. L. (2014). Concepções pedagógicas e mudanças nas práticas contábeis: Um estudo sobre o modelo educacional adotado em uma universidade pública e a formação crítico-reflexiva do contador. Revista de Contabilidade e Controladoria, 6(2), 54-66. doi.org/10.5380/rcc.v6i2.34177.

Stewart, J. P., \& Dougherty, T. W. (1993). Using case studies in teaching accounting: A quasi-experimental study. Accounting Education, 2(1), 1-10. doi.org/10.1080/09639289300000001.

Taylor, M., Marrone, M., Tayar, M., \& Mueller, B. (2018). Digital storytelling and visual metaphor in lectures: a study of student engagement. Accounting Education, 27(6), 552-569. doi.org/10.1080/09639284.2017.1361848.

Teixeira, A. P. P., Leal, E. A., \& Miranda, G. J. (2008). Controle de custos: Ferramenta para gestão das micro e pequenas empresas. Anais do Congresso Brasileiro de Custos, Curitiba, PR, Brasil, 15. Recuperado de: http://bit.ly/2MCG3Rm.

Tomita, L. M. S. (1999). Trabalho de campo como instrumento de ensino em Geografia. Geografia, 8(1), 1315. doi.org/10.5433/2447-1747.1999v8n1p13.

Valdevino, A. M., Brandão, H. A., Carneiro, J. S., Santos, A. T., \& Santana, W. J. P. (2017). Caso para ensino como metodologia ativa em administração. Revista Pensamento Contemporâneo em Administração, 4(3), 1-12. doi.org/10.12712/rpca.v11i3.1006.

Vendramin, E. O. (2018). Criando caso: Análise do método do caso como estratégia pedagógica no ensino superior da contabilidade. Tese de Doutorado em Ciências Contábeis, Faculdade de Economia, Administração e Contabilidade de Ribeirão Preto, Universidade de São Paulo, Ribeirão Preto, SP. Recuperado de: http://bit.ly/2I2snLp. 